\title{
Dr. Edward Hartley Angle, the founder of modern Orthodontics - part II
}

\author{
Dr. Edward Hartley Angle, fondatorul ortodonţiei moderne - partea a II-a
}

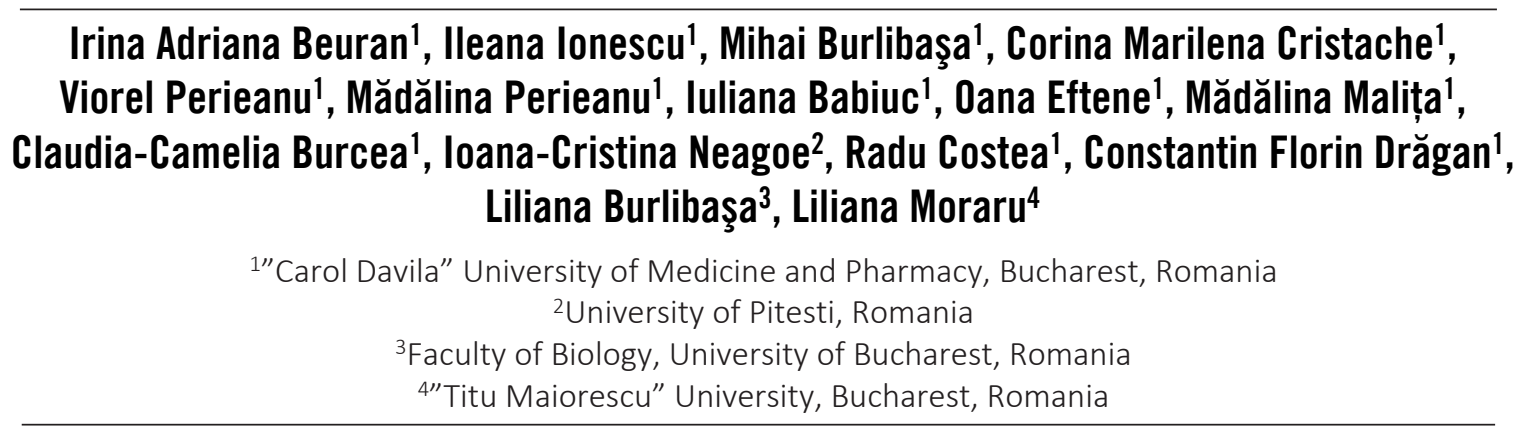

\begin{abstract}
Edward Hartley Angle was an eminent American scientist, dentist, great inventor, being rightly considered to be the father of modern orthodontics. The great American scientist was the author of an impressive number of patents (46) and was the coordinator of 7 editions of some impressive orthodontic treatises. Thus, in this material, which we structured in 2 distinct parts, we tried to present as concisely as possible the most important data from the biography of Dr. Edward Hartley Angle.
\end{abstract}

Keywords: orthodontics and dento-facial orthopedics, dentistry, inventor

\section{REZUMAT}

Edward Hartley Angle a fost un eminent om de ştiinţă american, medic stomatolog, inventator de foarte mare anvergură, fiind considerat, pe drept cuvânt, părintele ortodonţiei moderne. Marele savant american a fost autor al unui număr impresionant de brevete de invenţie (46) şi a fost coordonator a 7 ediţii ale unor impresionante tratate de ortodonţie. Astfel, în acest material pe care l-am structurat în 2 părţi distincte, am încercat să prezentăm cât mai succint cele mai importante date din biografia Dr. Edward Hartley Angle.

Cuvinte cheie: ortodonţie şi ortopedie dento-facială, stomatologie, inventator

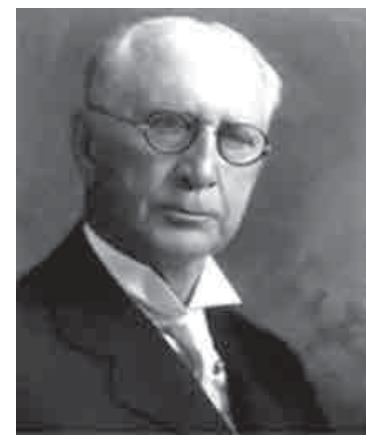

FIGURA 1.

Dr. Edward Hartley Angle (1855-1930) (4)

\section{INTRODUCERE}

În continuare, în baza studiului de bibliotecă extrem de laborios pe care noi, autorii, 1-am realizat, vom prezenta datele biografice ale Prof. Dr. Edward Hartley Angle, începând cu anul 1888. Concret, până la schimbarea dintre secole, mai exact până în anul 1900, activitatea didactică, ştiinţifică şi profesională a Prof. Dr. Edward Hartley Angle a fost una extrem de interesantă (1-9). 


\section{DEZVOLTAREA CARIEREI PROFESIONALE ŞI ŞTIINȚIFICE}

În anul 1888, ca o recunoaştere a meritelor sale profesionale, Dr. E.H. Angle a fost ales preşedinte al Societăţii Dentare din oraşul Minneapolis (Minneapolis City Dental Society).

Pe 5 martie 1889, Dr. E.H. Angle a brevetat prima dintre cele 46 de invenţii recunoscute prin brevet, ca aparţinând Dr. E.H. Angle. Este vorba despre unul dintre primele modele de şuruburi ortodontice.

În anul 1890, a apărut o a doua ediţie a unui manual de tehnică dentară, sub coordonarea aceluiaşi renumit specialist în dentistică, care a fost Dr. Loomis P. Haskell, sub redacţia căruia apăruse şi primul material al Dr. Angle (este vorba, de fapt, despre acel material ce reprezintă, conform specialiştilor, prima ediţie a tratatului de ortodonţie al Prof. E.H. Angle şi care fusese publicat fără a avea acordul acestuia, aspect asupra căruia am insistat anterior), care cuprindea şi o anexă de 30 de pagini privind activitatea de laborator de tehnică dentară în ortodonţie, anexă publicată de această data cu acordul şi sub semnătura profesorului E.H. Angle, în calitate de autor recunoscut al acestui material şi care, conform specialiştilor, este considerat ca fiind a doua ediţie a tratatului de ortodonţie aparţinând acestei mari personalităţi a stomatologiei universale.

În anul 1892, Dr. E.H. Angle a demisionat din poziţia de profesor universitar de ortodonţie, din cadrul Departamentului de Dentistică al Universităţii din Minnesota (Dental Department of University of Minnesota), Minneapolis, Minnesota, S.U.A., dedicându-se strict activităţii practice private de ortodonţie şi ortopedie dento-facială. Astfel, Dr. Edward Hartley Angle a devenit primul specialist recunoscut în ortodonţie din lume.

Tot în anul 1892, Dr. E.H. Angle a angajat-o în calitate de asistentă personală şi secretară pe Anna Hopkins (1852-1957), de doar 20 de ani, o persoană extrem de controversată apărută în viaţa reputatului dentist, care, ulterior, avea să îi devină şi soţie în anul 1908, fiind, se pare, principala cauză care a produs întâi separarea în anul 1900 şi apoi, 8 ani mai târziu, în anul 1908, divorţul de soţia sa, Florence A. Canning Angle.

În acelaşi an, 1892, a apărut o broşură de 51 de pagini, intitulată The Angle system of regulation and retention of the teeth, considerată de către specialişti ca fiind de fapt a treia ediţie a tratatului de ortodonţie aparţinând Dr. E.H. Angle.

Între anii 1892 şi 1898, Dr. E.H. Angle a fost profesor universitar de ortodonţie cu drepturi de- pline în cadrul Colegiului American de Chirurgie Dentară (American College of Dental Surgery) din oraşul Chicago, statul american Illinois. Ulterior, Colegiul American de Chirurgie Dentară (American College of Dental Surgery) avea să devină Facultatea de Medicină Dentară a Universităţii Northwestern (Northwestern University Dental School), Chicago, Illinois, SUA.

În anul 1894, Prof. Dr. E.H. Angle a fost desemnat în calitate de chirurg cu specialitate bucomaxilo-facială, axat în special pe terapeutica fracturilor oaselor maxilare, în cadrul Marii Companii de Căi Ferate din Nord (Great Northern Railroad).

În anul 1895, a fost publicată o carte de 112 pagini, intitulată The Angle system of regulation and retention of the teeth and treatment of fractures of the maxillae, carte considerată de către majoritatea specialiştilor ca fiind a patra ediţie a tratatului de ortodonţie a Dr. E.H. Angle. De fapt, prin acest volum, Dr. E.H. Angle şi-a consolidat poziţia de cel mai important specialist în ortodonţie şi ortopedie dento-facială din SUA, dar şi-a creat şi o reputaţie solidă de specialist în chirurgie buco-maxilo-facială, mai exact în tratamentul fracturilor oaselor maxilare. Această a patra ediţie a tratatului de ortodonţie a apărut tot în anul 1895 şi în Berlin, capitala Prusiei, fiind tradusă în limba germană, bucurându-se de un interes deosebit din partea dentiştilor germani. Ambele variante ale ediţiei a patra ale tratatului de ortodonţie - engleză şi germană -, publicate sub coordonarea Prof. Dr. Edward H. Angle, au apărut sub egida firmei de produse stomatologice S.S. White, Philadelphia, firmă deosebit de prestigioasă, existentă şi în zilele noastre, şi unde se pare că unul dintre principalii acţionari a fost nimeni altul decât reputatul dentist Dr. E.H. Angle.

Tot în anul 1895, Prof. Dr. Edward Hartley Angle s-a mutat împreună cu familia (cu soţia şi fiica), dar şi cu asistenta sa, Anna Hopkins, în oraşul St. Louis, Missouri, SUA, unde şi-a deschis propriul cabinet privat de dentistică în clădirea simbol a oraşului, Olivia Building, desfăşurând aici doar o activitate destul de limitată de ortodonţie clinică. Mai precis, marele savant şi-a împărţit timpul în această perioadă între oraşul St. Louis, unde se mutase alături de familia sa, şi oraşul Chicago, unde desfăşura activitate didactică în calitate de profesor universitar de ortodonţie cu drepturi depline, în cadrul Colegiului American de Chirurgie Dentară (American College of Dental Surgery), devenit ulterior Facultatea de Medicină Dentară a Universităţii Northwestern (Northwestern University Dental School), Chicago, Illinois, SUA. 
Între anii 1896 şi 1899, Dr. E.H. Angle a fost profesor universitar de ortodonţie cu drepturi depline în cadrul Departamentului de Dentistică al Colegiului de Medicină Marion Sims (Dental Department of Marion Sims College of Medicine) din St. Louis, Missouri, SUA. În paralel, Prof. Dr. E.H. Angle şi-a menţinut colaborarea didactică în ortodonţie, despre care am amintit anterior, în cadrul Colegiului American de Chirurgie Dentară (American College of Dental Surgery), Chicago, Illinois, SUA, până în anul 1898.

Tot în acest interval de timp, între anii 1896 şi 1899, Dr. E.H. Angle a desfăşurat activitate didactică în ortodonţie şi în cadrul Departamentului de Dentistică al Universităţii Washington (Dental Department of Washington University) din St. Louis, Missouri, SUA.

Foarte important a fost faptul că, în anul 1897, ediţia a cincea a tratatului de ortodonţie a Prof. Dr. E.H. Angle a fost publicată de către aceeaşi importantă firmă de produse stomatologice, S.S. White, din Philadelphia. Această ediţie a cincea a tratatului de ortodonţie a beneficiat şi de o traducere foarte precisă în limba germană, acesta apărând tot sub egida firmei S.S. White şi în Berlin, la acea vreme capitală a Prusiei.

Tot în anul 1897, lui Charles Angle i-a fost acordat şi titlul de doctor în medicină din partea Colegiului de Medicină Marion Sims (Marion Sims College of Medicine) din St. Louis, Missouri, SUA, aceeaşi instituţie de învăţământ superior medical unde acesta era la acel moment şi profesor universitar de ortodonţie cu drepturi depline. Concret, la momentul anului 1897, reputatul savant şi inventator american a devenit oficial posesor atât al unei diplome de specialist în dentistică, cât şi al unei diplome de medicină generală.

În anul 1899, Dental Cosmos Journal, o importantă revistă americană cu profil de dentistică, a publicat, poate, cel mai important articol din existenţa sa: Clasificarea malocluziilor după Angle (Angle's classification of malocclusion).

Tot în anul 1899, Claudius Ash a publicat traducerea în limba franceză a ediţiei a patra a tratatului de ortodonţie The Angle system of regulation and retention of the teeth and treatment of fractures of the maxillae, de 112 pagini. Această traducere în limba franceză a aparţinut lui Gustave Darin şi s-a intitulat Méthode du professeur Angle pour la régularisation et le traitement des dents et pour le traitement des fractures des maxillaires.

Pe 6 iunie 1899, Dr. E.H. Angle a mai brevetat o o variantă foarte apreciată de către specialişti a unui model de arc ortodontic, intitulat E-Arch.
În luna august a anului 1899, a avut loc Conferinţa Asociaţiei Naţionale a Dentiştilor (National Dental Assosciation) din SUA, conferinţă care s-a desfãşurat în localitatea Niagara Falls, statul american New York, şi unde lucrarea extrem de amplă pe teme de ortodonţie a Prof. E.H. Angle, foarte greu pregătită şi excelent documentată, nu a fost lăsată să fie prezentată sub nicio formă de către comitetul de organizare al acestei manifestări ştiinţifice deosebit de prestigioase. Foarte supărat de producerea acestui incident nedorit, Prof. Dr. Edward Hartley Angle a luat 2 decizii extrem de importante, decizii care, ulterior, au cântărit foarte mult în evoluţia carierei din secolul XX a marelui savant şi inventator american: înfiinţarea unei şcoli de studii postuniversitare de ortodonţie şi ortopedie dento-facială, precum şi înfiinţarea unei societăţi profesionale cu caracter naţional dedicată ortodonţiei.

În luna noiembrie a anului 1899, Prof. Dr. E.H. Angle a ţinut primul curs de perfecţionare postuniversitară în ortodonţie şi ortopedie dento-facială, în cadrul cabinetului său privat de stomatologie, cabinet situat în Olivia Building din St. Louis, Missouri, SUA. Cei 4 participanţi la acest prim curs de perfecţionare postuniversitară au fost: Thomas B. Mercer, Henry E. Lindas, Herbert A. Pullen şi Milton T. Watson.

În decembrie 1899, Dr. Edward Hartley Angle şi-a dat demisia din poziţia de profesor universitar de ortodonţie pe care o deţinea în cadrul Departamentului de Dentistică al Colegiului de Medicină Marion Sims (Dental Department of Marion Sims College of Medicine) din St. Louis, Missouri, SUA. Reputatul cercetător s-a dedicat strict activităţii private clinice şi de cercetare şi mai ales celei didactice.

Şi iată-ne intraţi în anul 1900, secolul XX. Prof. Dr. E.H. Angle a înfiinţ̧at în oraşul St. Louis Şcoala de Ortodonţie Angle, prima şcoală de acest gen, unde a început să organizeze cursuri de perfecţionare postuniversitară în ortodonţie şi ortopedie dento-facială. Primul curs, cu o durată de 5 săptămâni, a început pe data de 1 mai 1900 şi s-a finalizat în prima jumătate a lunii iunie din acelaşi an. Tot în acest an, mai exact în luna iulie, a avut loc şi separarea de prima sa soţie, Florence Canning Angle.

În luna decembrie a anului 1900, Prof. Dr. E.H. Angle a publicat cea de-a şasea ediţie a tratatului de ortodonţie, sub forma unei cărţi de 315 pagini, intitulată Treatment of malocclusion of the teeth and fractures of the maxillae. Angle's system, poate cea mai complexă lucrare dedicată ortodonţiei şi 
ortopediei dento-faciale apărută până la acel moment. Prin această nouă ediţie a tratatului de ortodonţie (eadiţia cu numărul şase), la doar 45 de ani, reputatul medic dentist american a demonstrat că a ajuns la maturitatea profesională, dovedind nu doar o putere de muncă exemplară, ci şi o intuiţie profesională de mare geniu.

Astfel, intrarea în secolul XX a însemnat pentru profesorul Edward Hartley Angle o perioadă de mari schimbări atât în viaţa profesională, cât şi în viaţa personală. Multe dintre aceste schimbări au fost de foarte bun augur, experimentatul dentist american ajungând ca până la moartea sa, pe data de 11 august 1930, să impună ortodonţia şi ortopedia dento-facială ca specialitate medicală extrem de bine conturată şi definită, nu doar în SUA, ci şi în majoritatea ţărilor din Europa.

\section{APOGEUL CARIEREI}

În continuare, vom prezenta activitatea profesională, didactică şi ştiinţifică a Prof. Dr. Edward Hartley Angle în secolul XX, mai exact între anii 1901 şi 1930. Aceasta a fost perioada de glorie a marelui savant american, în care meritele sale profesionale au fost recunoscute de către contemporanii săi (1-9).

În anul 1901, a fondat prima societate profesională şi ştiinţifică de ortodonţie din SUA (se pare că a fost şi prima din lume), intitulată Societatea Ortodonţilor (Society of Orthodontists), cea care a precedat Societatea Americană a Ortodonţilor (American Association of Orthodontists), înfiinţată în anul 1902, Prof. Dr. Edward Hartley Angle fiind ales primul preşedinte.

Tot în anul 1901, Dr. E.H. Angle a înfiinţat şi o a doua societate profesională şi ştiinţifică, dar de această dată era adresată mai mult practicienilor de stomatologie clasică (şi/sau generală) din oraşul St. Louis. Este vorba despre Societatea de Ştiinţe Dentare din St. Louis (Society of Dental Sciences of St. Louis). Iniţial, s-a dorit ca această societate să fie una de interes local dar, în timp, această asociaţie profesională şi ştiinţifică a dentiştilor din St. Louis şi-a dovedit forţa, membrii săi impunându-şi punctele de vedere în foarte multe probleme (legislative, profesionale şi ştiinţifice) în ceea ce priveşte organizarea stomatologiei pe teritoriul SUA.

În luna iulie a aceluiaşi an 1901, a avut loc în oraşul St. Louis prima Conferinţă a Societăţii Ortodonţilor (Society of Orthodontists), care, în anul 1902, a devenit Societatea Americană a Ortodonţilor (American Association of Orthodontists).

În anul 1902, Anna Hopkins, asistenta personală a Prof. Dr. E.H. Angle şi cea care în anul 1908 i-a devenit cea de-a doua soţie, a absolvit studiile de dentistică în cadrul Universităţii din Iowa (University of Iowa), obţinând cu această ocazie diploma de dentist.

În luna decembrie a anului 1902, Profesorul E.H. Angle a declinat oferta de a deveni editor pe probleme de ortodonţie şi ortopedie dento-facială al revistei International Dental Journal.

În perioada 29 august - 3 septembrie 1904, a fost preşedinte al Secţiunii VI Ortodonţie, din cadrul celui de-al IV-lea Congres Internaţional de Dentistică (Fourth International Dental Congress), desfăşurat în oraşul St. Louis.

Tot în 1904, a fost tradusă în limba germană ediţia a cincea a tratatului de ortodonţie a Prof. Dr. E.H. Angle (cea din anul 1895), cartea văzând lumina tiparului la Berlin, apărând tot sub egida firmei americane de produse stomatologice S.S. White.

În anul 1905, Prof. Dr. E.H. Angle a contribuit cu un capitol de ortodonţie şi ortopedie dento-facială la cartea intitulată American textbook of operative dentistry, carte apărută sub redacţia lui Edward C. Kirk (ediţia a fost revizuită ulterior, în anul 1911).

În primăvara anului 1906, Prof. Dr. E.H. Angle a demisionat din Societatea Americană a Ortodonţilor (American Association of Orthodontists) şi a încurajat înfiinţarea Societăţii Alumni (Alumni Society), apărută sub egida Şcolii de Ortodonţie Angle.

În iarna anului 2006 spre 2007, Prof. Dr. E.H. Angle a renunţat la a mai practica ortodonţia în oraşul St. Louis şi s-a concentrat pe scrierea şi apoi pe publicarea ediţiei a şaptea a tratatului de ortodonţie (aşa cum este considerat de către specialişti), sub forma unei cărţi de 628 de pagini, intitulată Treatment of malocclusion of the teeth, Angle's system.

În anul 1907, s-a stins din viaţă la vîrsta de 87 de ani tatăl său, Philip Casebeer Angle, lucru care 1-a afectat foarte mult pe reputatul dentist american.

Tot în anul 1907, au mai fost 2 evenimente foarte importante în viaţa Prof. Dr. E.H. Angle. În luna mai, a înfiinţ̧at firma E.H. Angle Regulating Appliance Co, firmă prin care acesta a produs şi a valorificat majoritatea dispozitivelor, sistemelor, instrumentelor şi materialelor inventate. În luna iunie 1907, a înfiinţat o revistă profesională şi ştiinţifică de ortodonţie, intitulată The American Orthodontist. Această revistă şi-a oprit activitatea în anul 1912, fiind înlocuită după moartea marelui savant, pe data de 17 noiembrie 1930, cu The An- 
gle Orthodontist, revistă care apare şi astăzi, şi despre care am amintit în partea introductivă a acestui material.

În anul 1908, s-a stins din viaţă şi mama sa, Iasabel Erksine Angle, la vârsta de 84 de ani. Tot în prima jumătate a acestui an, 1908, Prof. Dr. E.H. Angle a divorţat şi de prima sa soţie, Florence Canning Angle, de care doar se separase în anul 1900, iar pe data de 28 iunie s-a recăsătorit cu fosta sa asistentă şi secretară personală, Anna Hopkins.

Imediat după căsătorie, la insistenţele noii sale soţii, în vara anului 2008, Prof. Dr. Edward Hartley Angle s-a mutat din oraşul St. Louis, unde fosta sa soţie şi fiica sa au continuat să locuiască, în localitatea Larchmont, foarte aproape de oraşul New York.

În intervalul 15 septembrie 1908 - 31 octombrie 1908, Şcoala de Ortodonţie Angle a funcţionat chiar în oraşul New York, într-o clădire de birouri aflată la intersecţia West 72nd Street cu Broadway.

Pentru că lucrurile nu au mers chiar aşa cum s-au aşteptat în oraşul New York, în luna aprilie a anului 1909, familia Angle şi-a cumpărat o casă foarte spaţioasă în oraşul New London din statul american Connecticut, mai precis în 58 Bellevue Place, New London, Connecticut.

În toamna anului 1909, Prof. Dr. Edward Hartley Angle a mutat şi Şcoala de Ortodonţie Angle din oraşul New York, în noua localitate de reşedinţă, New London, într-una dintre cele mai reprezentative clădiri din oraş, Munsey Building. Tot spre sfârşitul anului 1909, au reînceput să funcţioneze şi cursurile de perfecţionare postuniversitară în ortodonţie şi ortopedie dento-facială, în cadrul Şcolii de Ortodonţie Angle, doar că modulul de curs a fost dublat: a crescut de la 5 săptămâni la 9 săptămâni.

În anul 1911, Şcoala de Ortodonţie Angle din localitatea New London, deschisă cu foarte mari eforturi şi sacrificii de către Prof. Dr. E.H. Angle, a fost închisă, motivul oficial fiind acela că, sănătatea reputatului dentist s-a deteriorat foarte mult în ultima perioadă. Se pare însă că, pe lângă o sănătate şubrezită, Dr. Angle avea şi mari probleme financiare, Şcoala de Ortodonţie Angle deschisă în noua locaţie nebucurându-se chiar de interesul cu care excelentul ortodont fusese obişnuit atunci când funcţiona în oraşul St. Louis.

În anul 1913, a fost publicată în limba germană, la Berlin, cartea considerată ediţia cu numărul 7 a tratatului de ortodonţie a Prof. Dr. E.H. Angle, un volum care avea 778 de pagini. Această ediţie, faţă de varianta apărută anterior în SUA, a fost mult îmbunătăţită, având adăugate mai multe capitole ale unor reputaţi specialişti ortodonţi germani, Josef Grunberg şi Albin Oppenheim.
Pe 22 februarie 1915, datorită meritelor şi contribuţiilor sale cu adevărat excepţionale din domeniul ortodonţiei şi ortopediei dento-faciale, Prof. Dr. Edward Hartley Angle a fost recompensat cu un doctorat onorific din partea Universităţii din Pennsylvania, SUA.

În anul 1916, din cauza sănătăţii precare, Prof. Dr. E.H. Angle a fost nevoit să se mute, împreună cu familia sa, într-o zonă cu o climă mai blândă, California. Familia Angle a optat pentru mutarea în oraşul Pasadena, California, într-un imobil aflat pe 1025 North Madison Avenue.

Un an mai târziu, în anul 1917, la solicitarea lui James C. Angle (pură coincidenţă de nume, fără nicio legătură de rudenie cu familia Angle), reputatul medic dentist a redeschis Şcoala de Ortodonţie Angle, în noul oraş de reşedinţă al familiei Angle, Pasadena.

În anul 1922, a fost înfiinţată de către absolvenţii Şcolii de Ortodonţie Angle o nouă societate profesională şi ştiinţifică în oraşul Pasadena, societate intitulată Societatea Ortodonţilor Edward H. Angle (Edward H. Angle Society of Orthodontists).

În perioada 1922-1923, absolvenţii Şcolii de Ortodonţie Angle au finanţat construcţia unui nou sediu al acestei unităţi de învăţământ superior medical de perfecţionare postuniversitară în ortodonţie şi ortopedie dento-facială la o nouă adresă: 550 Jackson Street, în oraşul Pasadena.

În anul 1924, Şcoala de Ortodonţie Angle a fost preluată de statul american California, în baza unui contract de închiriere pe o perioadă de timp prestabilită. Astfel, procesul didactic de perfecţionare postuniversitară în ortodonţie şi ortopedie dentofacială în cadrul Şcolii de Ortodonţie Angle a fost extins la 1 an, a devenit gratuit, iar studenţii facultăţilor de dentistică din statul american California au putut face practica obligatorie de la sfârşit de facultate în cadrul Şcolii de Ortodonţie Angle. Totodată, toţi pacienţii trataţi în cadrul Şcolii de Ortodonţie Angle au beneficiat de gratuitate pentru tratamentele de specialitate.

În anul 1927, Şcoala de Ortodonţie Angle a încetat să mai funcţioneze din cauza alterării foarte severe a stării de sănătate a Prof. Dr. E.H. Angle.

Pe 11 august 1930, Prof. Dr. Edward Hartley Angle s-a stins din viaţă la vârsta de 75 de ani în oraşul Pasadena, California, SUA, în urma unei insuficienţe cardiace. Marele savant american a fost înmormântat în Mountain View Cemetery, Altadena, California.

Pe 17 noiembrie 1930, în memoria marelui savant şi inventator Prof. Dr. Edward Hartley Angle, a fost înfiinţată la Chicago o revistă ştiinţifică de 
mare anvergură, dedicată exclusiv ortodonţiei şi ortopediei dento-faciale, intitulată The Angle Orthodontist, publicaţie care apare cu regularitate şi în prezent. De asemenea, şi Societatea Ortodonţilor Edward H. Angle (Edward H. Angle Society of Orthodontists) a fost reorganizată şi o regăsim funcţională şi în zilele noastre.

\section{CONCLUZII}

Profesor Dr. Edward Hartley Angle a fost şi rămâne una dintre cele mai proeminente figuri ale stomatologiei moderne universale. A fost deschiConflict of interest: none declared Financial support: none declared

\section{BIBLIOGRAFIE}

1. Peck S. A biographical portrait of Edward Hartley Angle, the first specialist in orthodontics, part 1. Angle Orthod. 2009 Nov; 79(6):1021-1027.

2. Peck S. A biographical portrait of Edward Hartley Angle, the first specialist in orthodontics, part 2. Angle Orthod. 2009 Nov; 79(6):1028-33.

3. Peck S. A biographical portrait of Edward Hartley Angle, the first specialist in orthodontics, part 3. Angle Orthod. 2009 Nov; 79(6):1034-6.

4. Wikipedia. Edward Angle. wikipedia.org. [Online] [Cited: 0723 , 2020.] https://en.wikipedia.org/wiki/Edward_Angle.

5. Peck S. The contributions of Edward H. Angle to dental public health Community Dent Health. 2009 Sep;26(3):130-1.

6. Han GW. Orthodontic Profiles - Edward Hartley Angle (1855-1930). Am J Orthodontics. 1965, Vol. 51, 7, pp. 529-535.

7. Orthodontics, The Edward H. Angle Society of. Edward H Angle. Angle Northen California. [Online] [Cited: 07 23, 2020.] https://www. anglenorcal.org/. zător de drum pentru această specialitate medicală reprezentată de ortodonţia şi ortopedia dento-facială nu doar în SUA şi Europa, ci în întreaga lume. Prof. Dr. Edward Hartley Angle este cel care a reuşit integrarea ortodonţiei şi ortopediei dento-faciale în familia specialităţilor medicale recunoscute astăzi în întreaga lume.

\section{Notă}

Toţi autorii au contribuţie egală cu primul autor în realizarea acestui articol.

8. bioxbio.com. Angle Orthodontist. Journal Impact Search. [Online] [Cited: 07 23, 2020.] https://www.bioxbio.com/journal/ANGLE-ORTHOD.

9. Sîmbeteanu I. Războiul Civil American, primul război total? www. historia.ro. [Online] [Cited: 07 23, 2020.] https://www.historia.ro/ sectiune/general/articol/razboiul-civil-american-primul-razboi-total.

10. wikipedia. Războiul Civil American. wikipedia.org. [Online] [Cited: 07 23, 2020.] https://ro.wikipedia.org/wiki/R\%C4\%83zboiul_Civil_American.

11. Arizona, The University of. Correspondence of Edward H. Angle. Special Collections - University Libraries. [Online] [Cited: 0703 , 2020.] https://speccoll.library.arizona.edu/collections/correspondence-edward-h-angle. 